\title{
Advertorial
}

\begin{abstract}
ABSTRAK
Pendahuluan: Penggunaan obat tradisional semakin berkembang baik sebagai obat maupun untuk tujuan yang lain, terlebih dengan adanya anjuran untuk kembali ke alam (back to nature). Perkembangan agromedicine sangat potensial di Indonesia sebab Indonesia memiliki biodiversitas terbesar keempat di dunia dan sumber daya alam yang melimpah. Obat-obatan herbal bersumber dari tanaman obat sebagai identitas medis di Indonesia dalam hal pengembangan agromedicine.

Pembahasan: Penggunaan obat tradisional Indonesia menjadi budaya bangsa karena Indonesia merupakan mega-center keanekaragaman hayati terbesar ke-2 di dunia. Pengembangan agromedicine dalam bidang obat-obatan herbal memerlukan kontribusi berbagai pihak terkait diantaranya mahasiswa, penyedia layanan media, pemerintah, produsen, dan lembaga riset.

Simpulan: Optimalisasi pemanfaatan agromedicine diperlukan untuk memenuhi kebutuhan obat nasional yang bermutu tinggi. Semua pihak memberikan kontribusi yang besar dalam tercapainya tujuan.

Kata Kunci: agromedicine, obat herbal, promosi kesehatan

\section{ROLE OF STUDENTS IN AGROMEDICINE DEVELOPMENT THROUGH HEALTH PROMOTION TO IMPROVE HEALTH QUALITY IN INDONESIA}

\begin{abstract}
Background: The use of traditional medicine is growing both as a medicine and for other purposes, first by presenting a recommendation to return to nature (back to nature). The development of agromedicine is very potential in Indonesia because Indonesia has the largest biodiversity in the world and abundant natural resources. Herbal medicines are sourced from medical identity medicinal plants in Indonesia in terms of developing agromedicine.

Discussion: The use of traditional Indonesian medicine has become a national culture because Indonesia is the second largest biodiversity center in the world. The development of agromedicine in the field of herbal medicines requires the contribution of various related parties including students, media service providers, governments, producers, and research institutions.

Conclusion: Optimizing the use of agromedicine is needed to meet the needs of highquality national medicines. All parties make a major contribution in achieving the goals.

Keywords: Agromedicine, herbal medicine, health promotion
\end{abstract}




\section{PENDAHULUAN}

Tantangan kesehatan yang dihadapi Indonesia di era milenial ini sangatlah kompleks terutama dari berbagai ancaman penyakit berbahaya yang belum bisa dituntaskan secara menyeluruh.[1] Menurut Kemetrian Kesehatan, tantangan Indonesia saat ini semakin meningkat di mana terjadi transisi epidemiologi dari sebelumnya beban penyakit disebabkan oleh penyakit menular bergeser pada beban Penyakit Tidak Menular (PTM)..[2] Penyakit tidak menular utama meliputi jantung, stroke, hipertensi, diabetes melitus, kanker, dan Penyakit Paru Obstruktif Kronis (PPOK). Jumlah kematian akibat PTM terus meningkat didukung oleh data Hasil Riset Kesehatan Dasar yang menunjukkan prevalensi penyakit stroke sebesar 8,3 per mil pada tahun 2008 menjadi 12,1 per mil pada tahun 2013. [3]

Permasalahan pelayanan kesehatan di Indonesia belum optimal dan merata dalam pengobatan. Hal ini dapat diatasi dengan pengembangan agromedicine yang sangat potensial di Indonesia agar pelayanan kesehatan dapat dirasakan secara menyeluruh oleh masyarakat. [4] Pengembangan agromedicine di Indonesia dapat mewujudkan optimalisasi sumber daya alam Indonesia yang melimpah. [5] Industri agromedicine memanfaatkan rangkaian proses pengolahan bahan-bahan nabati menjadi bahan baku obat. Indonesia sebagai negara dengan biodiversitas terbesar keempat di dunia ini dengan keunggulan berupa bahan hayati indigenous berkhasiat, sangat berpeluang besar untuk mengembangkan agromedicine terbesar di dunia. [6] Pengembangan agromedicine dapat mewujudkan kesejahteraan rakyat dalam pembangunan berkelanjutan di Indonesia. [6]

Budaya bangsa Indonesia telah mewariskan kebiasaan masyarakat untuk mengonsumsi jamu sebagai obat tradisional yang memiliki fungsi sebagai upaya pencegahan penyakit. Jika tanaman obat ini mampu diproduksi sebagai Obat Herbal Terstandar (OHT) dan Fitofarmaka maka akan mempunyai nilai jual yang lebih tinggi dan kemampuan daya saing yang lebih kuat baik di pasar dalam negeri maupun internasional. [7] Namun tanaman obat yang ada di Indonesia saat ini masih belum dikembangkan menjadi obat herbal. Edukasi konsumen serta pengetahuan akan produk herbal tradisional masih sangat dibutuhkan. Pemanfaatan tanaman obat ini semakin berkembang seiring dengan mulai berkembangnya produk. Tanaman obat tidak hanya dapat digunakan sebagai obat tradisional dan konsumsi rumah tangga, namun juga dapat dikembangkan dan diolah untuk berbagai macam kebutuhan, terutama jamu, obat-obatan, kosmetik, bahan untuk industri makanan/minuman, dan lainnya. ${ }^{[7]}$

Pada saat ini, obat-obatan dari bahan alam (obat tradisional) menjadi perhatian dunia dengan tren back to nature dengan adanya kecenderungan pola hidup sehat untuk kembali ke alam. [7] Badan Kesehatan Dunia (WHO) menyebutkan bahwa $80 \%$ dari penduduk di negara berkembang dan $65 \%$ penduduk di negara maju memilih menggunakan pengobatan tradisional dengan obat-obatan bahan alam. Faktor pendorong penggunaaan obat tradisional di negara maju antara lain adalah usia harapan hidup lebih panjang pada prevalensi penyakit kronis meningkat, adanya kegagalan penggunaan obat modern untuk penyakit tertertu (seperti kanker), dan meluasnya akses informasi mengenai obat tradisional di seluruh dunia. Data dari sekretariat Convention on Biological Diversity (CBD) menunjukkan angka penjualan global obat tradisional dapat menyentuh angka 60 miliar dollar Amerika Serikat setiap tahunnya. ${ }^{[8]}$ 
Penduduk Indonesia berjumlah lebih dari 220 juta jiwa merupakan potensi pasar tradisional yang besar untuk mengembangkan keberadaan obat-obatan tradisional. Indonesia memiliki keunggulan dalam obatobatan herbal dengan bahan baku yang berlimpah. Dilihat dari tradisi yang sudah mengakar kuat sejak dahulu dalam pemanfaatan tanaman obat tersebut, maka pengembangan agromedicine dapat dijadikan sebagai identitas medis Indonesia di mata dunia. [9] Adanya kecenderungan dunia untuk menempuh gaya hidup kembali ke alam (back to nature) yang mengkomsumsi obat alami memberikan angin segar bagi industri agromedicine yang memanfaatkan tumbuhan sebagai bahan baku utama, sehingga prospek pasar tumbuhan obat Indonesia di luar negeri semakin besar peluangnya. ${ }^{[10]}$

\section{PEMBAHASAN}

Penggunaan obat tradisional di Indonesia merupakan bagian dari budaya bangsa dan telah dimanfaatkan oleh masyarakat sejak berabad-abad yang lalu. Namun demikian, secara umum efektifitas dan keamanannya belum sepenuhnya didukung hasil penelitian yang memadai. Mengingat hal tersebut dan menyadari bahwa Indonesia sebagai mega-center keanekaragaman hayati terbesar ke-2 di dunia setelah Brazil, maka perlu adanya suatu kebijakan nasional yang dapat menjadi acuan semua pihak yang terkait didalamnya. [11]

Kebijakan Obat Tradisional Nasional yang selanjutnya disebut KOTRANAS merupakan kebijakan tentang obat tradisional secara menyeluruh dari hulu ke hilir. Kebijakan ini meliputi budidaya dan konservasi sumber daya obat, keamanan dan khasiat obat tradisional, mutu, aksesibilitas, penggunaan yang tepat, pengawasan, penelitian dan pengembangan, industrialisasi dan komersialisasi, dokumentasi dan database, dan pengembangan sumber daya manusia serta pemantauan dan evaluasi. [12]

Pemerintah melalui Direkrorat Jenderal Pengawas Obat dan Makanan juga berupaya dalam mendukung pengembangan agroindustri tumbuhan obat Indonesia dengan ditetapkannya 13 komoditi tumbuhan obat unggulan yaitu temulawak, jati belanda, sambiloto, mengkudu, pepagan, daun ungu, sanrego, pasak bumi, daun jinten, kencur, pala, jambu mete, dan tempuyung dengan pertimbangan bahwa komoditi tersebut bernilai ekonomi tinggi, mempunyai peluang pasar dan potensi produksi yang tinggi, serta berpeluang dalam pengembangan teknologi. [12, 13]

Berbagai kebijakan telah dilakukan untuk memberikan dampak secara signifikan dalam perkembangan agromedicine di Indonesia. Faktor kendala dalam perkembangan agromedicine karena tidak meratanya persebaran informasi tentang kebijakan agromedicine dalam obat-obatan tradisional di masyarakat maupun produsen obat, kurangnya informasi yang relavan membuat kesadaran akan manfaat obat-obatan tradisional masih sangat kurang, minimnya pengetahuan masyarakat tentang keunggulan pengembangan agromedicine ini membuat masyarakat belum memilki kepercayaan pemanfaatan secara fungsional terhadap obatobatan tradisional, minimnya pengetahuan para produsen terhadap kebijakan-kebijakan obatobatan tradisional, serta rendahnya informasi kebijakan-kebijakan terbaru membuat industri-industri agromedicine menjadi tertinggal. Oleh karena itu, diperlukan perluasan informasi untuk mewujudkan pengembangan agromedicine dalam bidang obatobatan tradisional secara merata dari semua pihak agar dapat bersinergi. [4,14]

Sebuah kebijakan akan berjalan sebagaimana mestinya apabila objek kebijakan dapat bersinergi 
dengan pelaksanaannya. Tindakan kooperatif dari masyarakat dan produsen obat-obatan herbal akan tercipta apabila mereka memahami kebijakan yang telah ditetapkan. Di era milenium ini informasi berkembang secara pesat dan tanpa batas. Kekuatan media komunikasi saat ini sangatlah besar dan cepat meluas. Mahasiswa sebagai generasi milenial dan garda terdepan pembangunan negeri ini dapat berperan dalam memanfaatkan fakta ini untuk penyebaran informasi pengembangan agromedicine disemua lapisan. Penyebaran informasi tersebut dapat dilakukan dengan promosi kesehatan. Dalam promosi kesehatan tersebut mahasiswa dapat mensosialisasikan kebijakankebijakan pemerintah tentang tanaman obat dan benar dalam pengolahan, serta manfaat-manfaat dan keunggulan agromedicine sebagai upaya peningkatan mutu kesehatan di Indonesia secara daring di berbagai media komunikasi dan sosial media yang saat ini populer.

Menurut lembaga riset pasar $e$ Marketer, populasi netter tanah air mencapai 83,7 juta orang pada 2014. Angka yang berlaku untuk setiap orang yang mengakses internet setidaknya satu kali setiap bulan itu mendudukkan Indonesia di peringkat ke-6 terbesar di dunia dalam hal jumlah pengguna internet. Pada 2017, e-Marketer memperkirakan netter Indonesia akan mencapai 112 juta orang, mengalahkan Jepang di peringkat ke-5 yang pertumbuhan jumlah pengguna internetnya lebih lamban. [15] Oleh karena itu, melihat pertumbuhan pengguna internet di Indonesia yang tinggi, dapat menjadi peluang pemerataan informasi kebijakan dan perkembangan agromedicine di Indonesia. [13]

Tantangan pembangunan kesehatan dan permasalahan pembangunan kesehatan semakin berat dan kompleks serta kadangkadang tidak terduga. Lebih daripada itu, pembangunan kesehatan tidak dapat mencapai tujuannya bila hanya diselenggarakan oleh sektor kesehatan saja, apalagi hanya oleh Departemen Kesehatan. Oleh karena itu, pembangunan kesehatan hanya akan dapat mencapai tujuannya bila diselenggarakan oleh pemerintah secara lintas sektor bersama segenap potensi masyarakat termasuk swasta, bahkan oleh semua potensi bangsa. ${ }^{[14,16]}$

Dalam upaya pelayanan kesehatan, ketersediaan obat dalam jenis yang lengkap, jumlah yang cukup, terjamin khasiatnya, aman, efektif, dan bermutu dengan harga terjangkau serta mudah diakses adalah sasaran yang harus dicapai. Untuk mencapai hal tersebut, dibutuhkan pula pemecahan masalah yang terkait dengan keberlangsungan pembiayaan (sustainability of financing), sistem distribusi perbekalan kesehatan yang handal (reliable health \& supply system) serta sistem baku mutu yang digunakan. [6]

Sumber daya alam Indonesia harus dimanfaatkan secara optimal dan berkelanjutan untuk kesejahteraan rakyat, oleh karena itu perlu dilakukan upaya peningkatan pemanfaatan sumber daya alam dibidang obat tradisional untuk peningkatan pelayanan kesehatan dan ekonomi.

Metode pengembangan agromedicine dalam promosi kesehatan dapat dilakukan sebagai suatu upaya bentuk untuk meingkatkan mutu kesehatan. Penyampaian materi promosi kesehatan dibuat bertahap sesuai proses pembelajaran dengan harapan dapat lebih mengena dalam penguasaan materi dan aplikatif, sehingga mempermudah untuk mempelajari tahapan selanjutnya. Materi yang berhubungan dengan rencana tindakan promosi kesehatan akan digunakan sebagai dasar intervensi yang berhubungan dengan pelayanan kesehatan. Jenis metode 
promosi kesehatan yang dapat dilakukan antara lain:

1. Metode pendidikan individual Dalam promosi kesehatan, metode pendidikan yang bersifat individual digunakan untuk membina perilaku baru atau membina seseorang yang mulai tertarik kepada suatu perubahan perilaku. Hal ini dimaksudkan agar tiap individu dapat menerima gagasan pengembangan agromedicine sehingga bisa menerapkannya dalam kehidupan sehari-hari. Bentuk pendekatan ini, antara lain:

a. Bimbingan atau penyuluhan Dengan cara ini kontak yang terjadi berlangsung lebih intensif sehingga penyaluran gagasan dapat lebih optimal.

b. Wawancara (interview)

Wawancara diperlukan untuk menggali informasi lebih apakah ia setuju atau tidak dengan gagasan tentang pengembangan agromedicine dan apa saja saran yang dapat disampaikan.

2. Metode pendidikan kelompok Dalam memilih metode pendidikan kelompok, harus diingat besarnya kelompok sasaran serta tingkat pendidikan formal dari sasaran. Hal ini dimaksudkan agar kelompok dapat menerima gagasan pengembangan agromedicine sehingga bisa menerapkannya dalam kehidupan sehari-hari. Bentuk pendekatan ini, antara lain:

a. Kelompok Besar

- Ceramah

- Seminar

b. Kelompok Kecil

- Diskusi kelompok

- Curah Pendapat Storming $)^{[17]}$

(Brain

Dalam melakukan promosi kesehatan diperlukan juga media promosi kesehatan. Media promosi kesehatan dimaksudkan untuk mempermudah penerimaan pesanpesan kesehatan kepada masyarakat. Media yang dapat dipakai terbagi menjadi tiga macam, yakni:
1. Media cetak

Media cetak sebagai alat untuk menyampaikan pesan-pesan pengembangan agromedicine antara lain:
a. Buklet
b. Leaflet
c. Flyer (selebaran)
d. Flip chart (lembar balik)
e. Rubrik atau tulisan-tulisan pada surat kabar atau majalah
f. Poster

2. Media elektronik Media elektronik sebagai sasaran untuk menyampaikan pesan-pesan atau informasi pengembangan agromediciene secara lebih menarik, antara lain:
a. Televisi
b. Radio
c. Video
d. Slide
e. Film strip

3. Media luar ruang berupa papan (billboard) ${ }^{[17]}$

Media menyampaikan pesan di luar ruang, bisa melalui media cetak maupun elektronik misalnya papan reklame, spanduk, pameran, banner dan televisi layar lebar, umbulumbul, yang berisi pesan, slogan atau logo. Kelebihan dari media ini adalah lebih mudah dipahami, lebih menarik, sebagai informasi umum dan hiburan, bertatap muka, mengikut sertakan seluruh panca indera, penyajian dapat dikendalikan dan jangkauannya relatif besar. Kelemahan dari media ini adalah biaya lebih tinggi, sedikit rumit, perlu alat canggih untuk produksinya, persiapan matang, peralatan selalu berkembang dan berubah, memerlukan keterampilan penyimpanan dan keterampilan untuk mengoperasikannya.

\section{KESIMPULAN}

Perkembangan Agromedicine di Indonesia memerlukan perhatian khusus dari pemerintah karena agromedicine memberikan beragam manfaat dan Indonesia memiliki potensi yang luar biasa dengan melimpahnya sumber daya alam. Optimalisasi pemanfaatan sumber 
daya alam di Indonesia dalam sektor agromedicine diharapkan dapat memberikan meningkatkan mutu kesehatan masyarakat Indonesia. Melalui perkembangan agromedicine diharapkan dapat menjadi solusi pemanfaatan sumber daya alam di Indonesia untuk meningkatkan mutu kesehatan masyarakat Indonesia

Dengan mengoptimalkan pemanfaatan agromedicine, Indonesia tentunya bisa menjadi negara terbesar dalam bidang obat herbal dengan memanfaatkan kekayaan alam sendiri. Hal tersebut akan selaras dengan tercapainya tujuan peningkatan mutu kesehatan untuk mewujudkan kesejahteraan rakyat Indonesia.

\section{DAFTAR PUSTAKA}

1. Kementerian Kesehatan Republik Indonesia. 18 Mei $2020<$ https://www.kemkes.go.id/article/vi ew/18011500006/inilah-upayanegara-melindungi-generasibangsa-dari-ancaman-penyakitberbahaya.html>

2. Keputusan Direktur Jenderal Pencegahan dan Pengendalian Penyakit Nomor HK. 02.03/D1/I.1/527/2018. Rencana Aksi Program P2P 2015-2019 (revisi I - 2018). 2018. Direktorat Jenderal Pencegahan dan Pengendalian Penyakit

3. Kementerian Kesehatan Republik Indonesia. Profil Kesehatan Indonesia tahun 2014. Jakarta : Kemenkes RI. 2015.

4. Herdiani, Elvina. Potensi Tanaman Obat Indonesia. 2012. 12 April 2020.<http://www.bbpplembang.info/index.php/arsip/ artikel/artikel-pertanian/585potensi-tanaman-obat-indonesia.>

5. Indonesia Negara Mega Biodeversity. 3 April 2020 <http://lipi.go.id/berita/indonesianegara-mega-biodiversity-di-dunia/5181>

6. Gunawan, W.. Bioprospeksi: Upaya Pemanfaatan Tumbuhan Obat Secara Berkelanjutan Di Kawasan Konservasi. 2014. 12 April 2020 <http://www.forda-mof.org/files/3 Bioprospecting_Upaya_Pemanfaat
an_Tumbuhan

Gunawan.pdf.>

_Obat-Wawan_

7. Salim Z dan Munawi E. 2017. Info Komoditi Tanaman Obat. Badan Pengkajian dan Pengembangan Perdagangan Kementerian Perdagangan Republik Indonesia

8. Ismail. Faktor yang Mempengaruhi Keputusan Masyarakat Memilih Obat Tradisional di Gampong Lam Ujong. Idea Nouring Journal. Vol VI No 1. 2015.

9. Harian Jurnal Asia. 17.000 Jenis Tanaman Obat Disia-Siakan. 2017. $12 \quad$ April 2020 <https://www.jurnalasia.com/bisnis/ 17-000- jenis-tanaman-obat-disiasiakan/ >

10. National Geographic. Indonesia Gudangnya Habitat Tanaman Obat Dunia. 2013. 12 April 2020 <http://nationalgeographic. co.id/berita/2013/09/indonesiagudangnya-habitat-tanaman-obatdunia.>

11. Kementerian Perdagangan Republik Indonesia. Obat Herbal Tradisional Ditjen PEN/MJL/005/9/2014 September. 2014.

12. Keputusan Menteri Kesehatan Republik Indonesia. Kebijakan Obat Tradisional Nasional Tahun 2007. 6 April 2020

<http: //jdih.pom.go.id/ produk/ Keputusan\%20Menteri/KEPMENK ES\%203812007\%20KEBIJAKAN\% 20OBAT\%20TRADISIONAL.pdfs

13. Sumber Obat Herbal melimpah di Indonesia. 7 April 2020

<http://nationalgeographic.co.id/ber ita/2012/05/sumber-obat-herbalmelimpah-di-indonesia>

14. Kemala, S, et al. Studi Serapan, Pasokan dan Pemanfaatan Tanaman Obat di Indonesia. Laporan Teknis Penelitian Bagian Proyek Penelitian Tanaman Rempah dan Obat APBN 200, 2003

15. Suwandi Sumartias. Keamanan Siber dan Pembangunan Demokrasi di Indonesia. Pusat Penelitian Badan Keahlian DPR RI. 2018

16. Sharma, A., B. Global Medicinal Plants Demand May Touch \$5Trillion By 2050. Indian Express .2004 . 
17. Susilowati D. Promosi Kesehatan: Modul Ajar Cetak Keperawatan. Kementerani Kesehatan Republik Indonesia. 2016

18. Pujiasmanto, Pengembangan B. Stretegi Tumbuhan Obat dalam Menunjang Pertanian Berkelanjutan. 2016.
12 April 2020

$<$ https://library.uns.ac.id/strategipengembangan-budidaya-

tumbuhan-obat-dalam-menunjangpertanian-berkelanjutan/> 